\title{
SANDG4-0729C
}

\section{SIMULATION OF CONCRETE PERFORATION BASED ON A CONTINUUM DAMAGE MODEL \\ Simulation of concrete perforation}

\author{
E. P. CHEN
}

Solid and Structural Mechanics Department

Sandia National Laboratories, Albuquerque, New Mexico, U.S.A.

\section{DISCLAIMER}

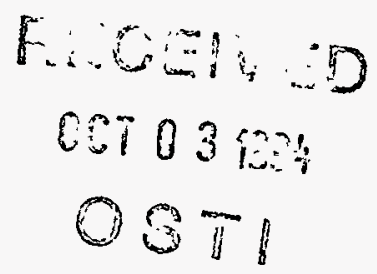

\begin{abstract}
This report was prepared as an account of work sponsored by an agency of the United States Government. Neither the United States Government nor any agency thereof, nor any of their employees, makes any warranty, express or implied, or assumes any legal liability or responsibility for the accuracy, completeness, or usefulness of any information, apparatus, product, or process disclosed, or represents that its use would not infringe privately owned rights. Reference herein to any specific commercial product, process, or service by trade name, trademark, manufacturer, or otherwise does not necessarily constitute or imply its endorsement, recommendation, or favoring by the United States Government or any agency thereof. The views and opinions of authors expressed herein do not necessarily state or reflect those of the United States Government or any agency thereof.
\end{abstract}

\begin{abstract}
Numerical simulation of dynamic fracture of concrete slabs, impacted by steel projectiles, was carried out in this study. The concrete response was described by a continuum damage model. This continuum damage model was originally developed to study rock fragmentation and was modified in the present study with an emphasis on the post-limit structural response. The model was implemented into a transient dynamic explicit finite element code LS-DYNA2D [1] and the code was then used for the numerical simulations. The specific impact configuration of this study follows the experiment series conducted by Hanchak et al. [2]. Comparisons between calculated results and measured data were made. Good agreements were found.
\end{abstract}

\section{Introduction}

Because of its potential utilization in energy exploration and defense applications, the phenomenon of brittle fracture in solids under dynamic loads has been an ongoing topic of interest. Unlike brittle fracture under quasi-static loading conditions where the propagation of a single crack dominated the process, dynamic brittle fracture under high strain rate loads involves multiple crack interactions and usually results in fragmentation. In order to predict accurately the responses of materials and structures under dynamic loads, it is important to identify dominant mechanisms and failure modes. Dynamic fracture of concrete slabs under projectile impact consists of various distinct failure modes. Post-test observations show that craters are formed at the top and bottom surface of the slab while a tunneling phase exists at the middle of the slab. The formation of the craters is due partly to fractures and fragments caused by the reflected tensile waves from the top and bottom free surfaces. The tunnel is developed from the expansion of the cavity formed by the quasi-steady penetration 


\section{DISCLAIMER}

Portions of this document may be illegible in electronic image products. Images are produced from the best available original document. 
of the projectile. The sizes of the cratering and tunneling phases are dependent on the thickness of the slab, the nose geometry and impact velocity of the projectile. For very thick slabs, tunneling phase dominates the problem and plasticity based cavity expansion techniques, Luk and Forrestal $[3,4]$, provided satisfactory solutions. For thinner concrete slabs, the size of the tunneling phase is comparable to or smaller than the dimensions for the cratering phases, tensile fracturing of concrete should be treated in order to provide reasonable solutions.

As a first order approximation to include tensile fracturing for concrete, Chen [5] performed a numerical simulation of the concrete perforation problem by adopting the soil and crushable foam model [6] for concrete. The soil and crushable foam model decouples the volumetric and deviatoric response of the material. The deviatoric response is elastic-perfectly plastic with a pressure dependent yield surface. The volumetric response allows nonlinear compaction with failure defined by a tensile pressure-cutoff. Although good agreement between calculated and measured data were obtained [5], questions were raised about the appropriateness of the decoupling of the deviatoric and volumetric responses and the lack of specific fracture mechanism and strain-rate effect inherent in the soil and crushable foam model.

In an effort to address these issues, this paper presents an alternative approach wherein the concrete response is modeled by a microcrack based continuum damage description [7]. The continuum damage model was based on the premise that the inelastic brittle response exhibited by rock under dynamic loads is due principally to the stress-induced sub-scale cracks. Eocally, the growth and interaction of these subscale cracks relieve portions of the material volume and reduce its capability to carry load. Globally, this effect is reflected insthe degradation of the material stiffness. In this manner, the dynamic fracture process was modeled as a continuous accrual of damage, where damage is considered to be the degree of reduction of the material stiffness. The model has been applied to explosive rock fragmentation and dynamic concrete fracturing and reasonable correlations between calculated and measured data were obtained [7-9]. Several modifications were made to the original model to increase its versatility. Details of the modifications are given in the paper.

The modified continuum damage model was implemented into the transient dynamic finite element code LS-DYNA2D'[1] to perform the concrete perforation analysis. Physical separation of the material in concrete was simulated by coupling the erosion algorithm in LS-DYNA2D, which deletes failed elements and rebuilds contact surfaces, with failure criteria in compression and tension based on effective plastic strain and damage levels, respectively. Numerical simulations of experiments conducted by Hanchak et al. [2] were performed. The experiments consist of 25.4 mm diameter, $143.7 \mathrm{~mm}$ long, $0.5 \mathrm{~kg}, 3.0$ caliber-radius-head, ogival nose steel rods impact on $610 \times 610 \times 178 \mathrm{~mm}^{3}$ reinforced concrete slabs at velocities between 300 and $1000 \mathrm{~m} / \mathrm{s}$. Post-test observations showed that under the specified impact conditions, significant front and backsurface cratering occurred in the target block. Comparisons between calculated and measured data are made. Good agreement is observed. 


\section{Continuum damage model description}

The basic assumption of the damage model is that the rock is permeated by an array of randomly distributed cracks which grow and interact with one another under tensile loading. The model does not attempt to treat each individual crack, but rather treats the growth and interaction of cracks as internal state variables which represent damage accumulation in the material. The damage is reflected in the degradation of the material stiffness following the equations derived by Budiansky and O'Connell [10] for a random array of penny-shaped cracks in an isotropic elastic medium

$$
\begin{aligned}
& \frac{K}{K}=1-\frac{16}{9}\left(\frac{1-\nabla^{2}}{1-2 \nabla}\right) C_{d} \\
& \frac{\bar{G}}{G}=1-\frac{32}{45} \frac{(1-\nabla)(5-\nabla)}{(2-\nabla)} C_{d} \\
& \frac{E}{E}=1-\frac{16}{45} \frac{\left(1-\nabla^{2}\right)(10-3 \nabla)}{(2-\nabla)} C_{d}
\end{aligned}
$$

where $\mathrm{K}, \mathrm{G}, \mathrm{E}$ and $\mathrm{v}$ are material bulk modulus, shear modulus, Young modulus and Poisson's ratio, respectively. Barred quantities such as $\overline{\mathrm{K}}$ represent degraded properties and $C_{d}$ is the crack density parameter. Additionally, the crack density parameter is related to the virgin and damaged Poisson's ratio through:

$$
C_{d}=\frac{45}{16} \frac{(v-\nabla)(2-\nabla)}{\left(1-\nabla^{2}\right)[10 v-\nabla(1+3 v)]}
$$

The damage variable is defined as

$$
D=\frac{16}{9}\left(\frac{1-\nabla^{2}}{1-2 \nabla}\right) C_{d}
$$

such that $\overline{\mathrm{K}}=\mathrm{K}$ ( $1-\mathrm{D})$. The crack density parameter is assumed to be proportional to the product of $\mathrm{N}$, the number of cracks per unit volume, and $\mathrm{a}^{3}$, the cube of the average crack dimension in a representative volume. Following Grady and Kipp [11], $N$ is expressed as a Weibull statistical distribution function activated by the bulk strain measure $\varepsilon_{\mathrm{v}}=\left(\varepsilon_{\mathrm{x}}+\varepsilon_{\mathrm{y}}+\varepsilon_{\mathrm{z}}\right) / 3$, according to

$$
N=k\left(\varepsilon_{v}\right)^{m}
$$

in which $\mathrm{k}$ and $\mathrm{m}$ are material constants to be determined from strain rate dependent tensile fracture stress data. The average crack dimension a, is estimated from the nominal fragment diameter for dynamic fragmentation in a brittle material [12] as 


$$
2 a=\left(\frac{\sqrt{20} K_{I C}}{\rho C \dot{\varepsilon}_{v \max }}\right)^{\frac{2}{3}}
$$

where $\rho$ is the mass density, $C$ is the uniaxial wave speed $(E / \rho)^{1 / 2}$, and $K_{I C}$ is the fracture toughness of the material. Also, $\dot{\varepsilon}_{v \max }$ is the maximum volumetric strain rate experienced by the representative volume element. Equations (1) through (5) can also be cast into rate form to relate stress and strain rates. When bulk tension occurs in the material, it is possible to calculate, at each time step, the crack density parameter $C_{d}$ by making use of Equations (6) and (7) and then damage parameter $\mathrm{D}$ through Equation (5). The material stiffness is then degraded according to Equations (1) through (5). In compression, the material behaves as an elastic/perfectly plastic solid. Details of the model development are given in [7] and will not be repeated here.

Modifications have been made to the above model to render it a more versatile tool. Because the equations derived by Budiansky and O'Connell [10] are limited to dilute crack concentrations, the crack density parameter has a limiting value of 9/16. To extend the range of crack densities, an expression based on percolation theory [13]

$$
\nabla=v \exp \left(-\frac{16}{9} \beta C_{d}\right), \quad 0 \leq \beta \leq 1
$$

was used to approximate Equation (4). ₹The value of $\beta$ controls the unloading and reloading behavior and relaxes the restriction of elastic unloading in the original model [7].

For many brittle solids, pressure-dependent inelastic response under compressive loads is observed. An improvement is made by extending the elastic/perfectly plastic compressive response to one that employs a Drucker-Prager yield surface [14]:

$$
F=\sigma^{2}-\left(c_{1}+c_{2} P\right)^{2}=0
$$

with $\delta$ the effective stress, $P$ the mean stress and $c_{1}$ and $c_{2}$ material constants determined from experimental data. To avoid too much dilation, a von Mises flow rule of the type

$$
\dot{\varepsilon}_{i j}^{p}=\dot{\lambda} \frac{s_{i j}}{\sqrt{s_{i j} s_{i j}}}
$$

is adopted. In Equation (10), $\dot{\varepsilon}_{i j}^{p}$ is the plastic strain rate tensor, $\dot{\lambda}$ is the plastic loading rate parameter, and $s_{i j}$ is the deviatoric stress tensor.

Without going into more details, this model and its modifications have been vectorized and implemented into the explicit finite element code LS-DYNA2D [1] for 
efficient computations.

\section{Characteristics of the damage model}

Characteristics of the continuum damage model described in the last section are examined here for concrete. The concrete properties used are those for the concrete slab tested in [2]. Two types of concrete targets were used in the experiments by Hanchak et al. [2]. One set of targets has an unconfined compressive strength of 48.0 $\mathrm{MPa}$ while the same for the other set is $140.0 \mathrm{MPa}$. Only the higher strength set is analyzed in this study. Nominal material properties such as the mass density, the Young's modulus, the Poisson's ratio and the fracture toughness are taken to be 2520 $\mathrm{kg} / \mathrm{m}^{3}, 20.68 \mathrm{GPa}, 0.18$ and $2.747 \mathrm{MPa}-\mathrm{m}^{1 / 2}$, respectively. Shear strength was measured by Hanchak et al. and an linear relationship of $\tau=220.8+0.313 \mathrm{p}(\mathrm{MPa})$ was fitted to the data, Fig. 1, and used in the calculations. Because perforation induces high pressures in the concrete, the approximation attempted to fit the data in

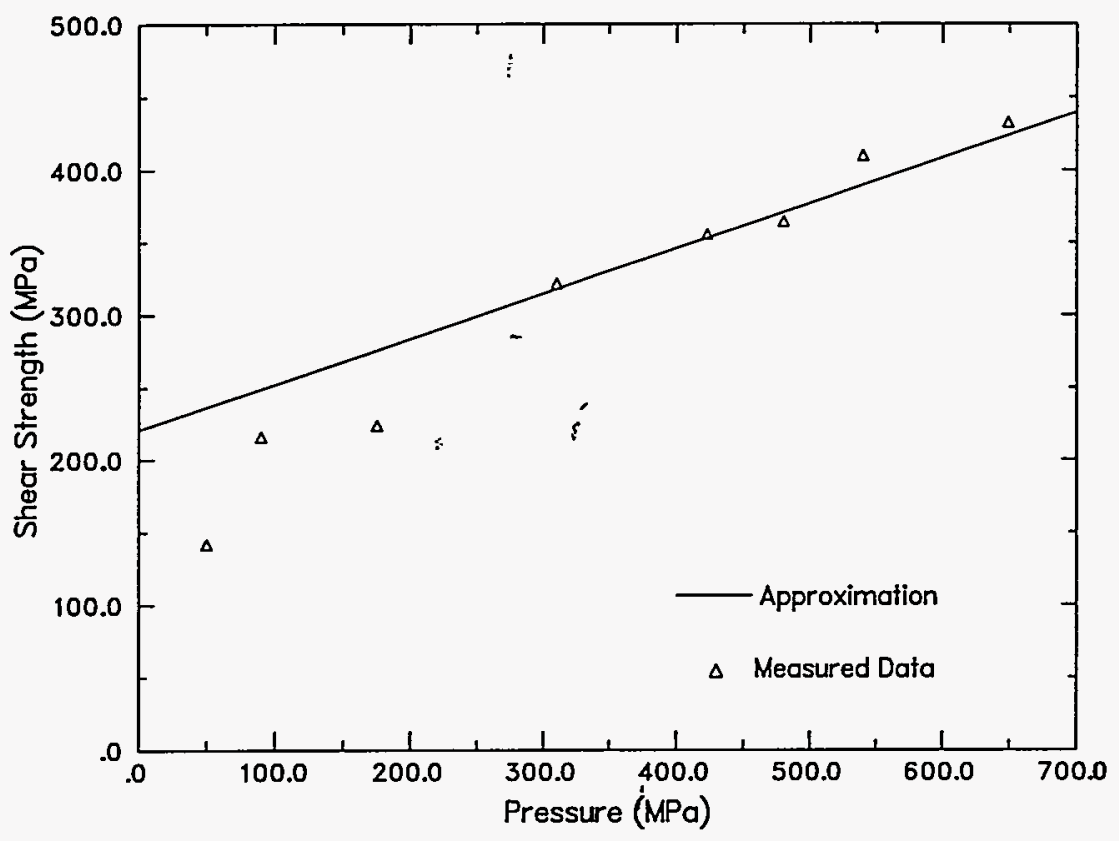

Fig. 1. Concrete shear strength versus pressure data.

the high pressure region at the expense of low pressure values. Strain-rate dependent tensile fracture stress data are required to determine the constants $\mathbf{k}$ and $\mathrm{m}$ in Equation (6). In lieu of measured data, it is possible to estimate this data using an expression derived in [15] for the tensile fracture stress $\sigma_{c}$ :

$$
\sigma_{c}=\left(\frac{9 \pi E K_{I C}^{2}}{16 N_{s}^{2} C_{s}}\right)^{\frac{1}{3}} \dot{\varepsilon}^{\frac{1}{3}}
$$

where $N_{s}$ is a shape factor (1.12 for penny-shaped cracks) and $C_{s}$ is the shear wave velocity of the material. Based on this equation and the material properties given 
above, $\mathrm{m}$ and $\mathrm{k}$ are determined to be 6.0 and $5.75310^{21} / \mathrm{m}^{3}$, respectively.

Using these material properties and 0.5 for $\beta$, the response of the concrete under bulk tension can now be examined. Fig. 2 shows the pressure-volumetric strain relationship under uniaxial homogeneous straining for three strain rates. In this

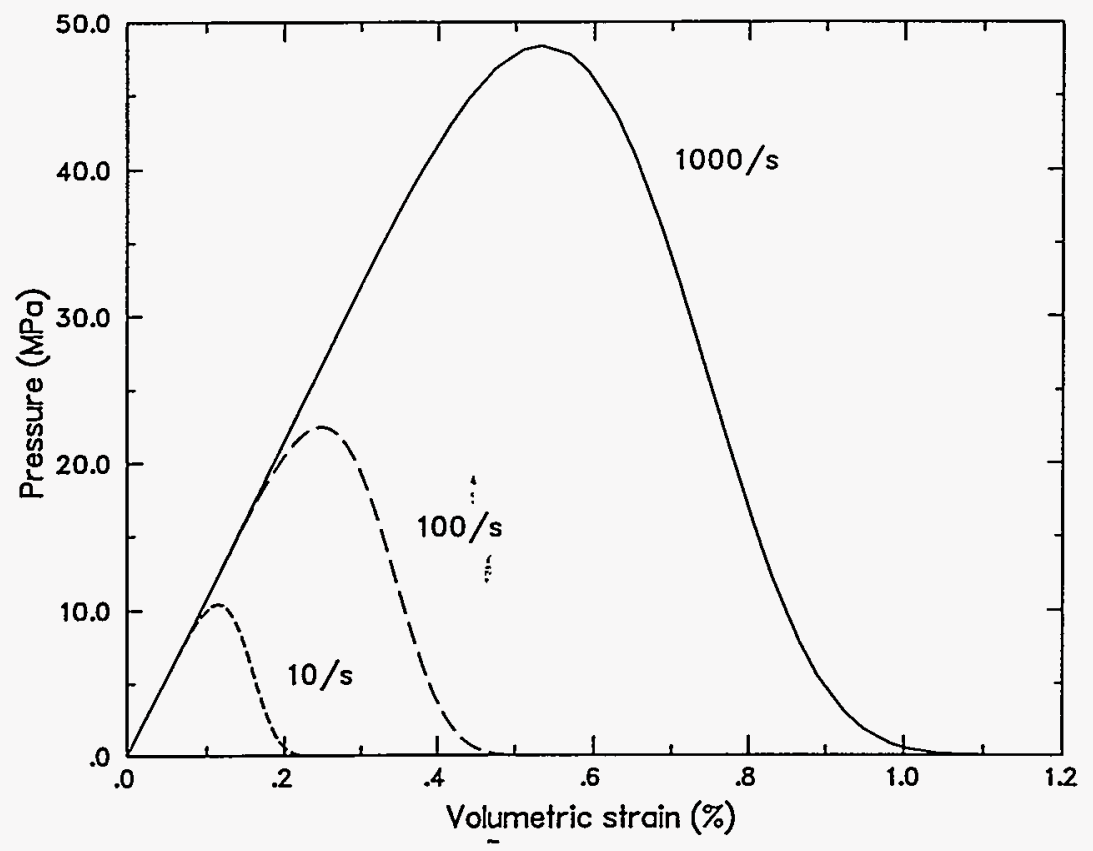

Fig. 2. Concrete bulk response under tension.

figure, positive pressure denotes bulk tension. Strain-softening is observed as a consequence of the micro-cracking damage accumulation. The material's capability to carry bulk tension increases with the strain rate. Damage accumulation as a function of volumetric strain is shown in Fig. 3. The loading/unloading/reloading behavior for 1000/s strain rate is exhibited in Fig. 4 and 5 in terms of pressure- and damage-volumetric strain plot, respectively. It is seen that the damage evolution is an irreversible process. During reloading, no more damage accumulation will take place until the strain level have exceeded the previous maximum. The value for $\beta$ controls the unloading response. For $\beta=0$, elastic unloading along damaged bulk modulus will result. For $\beta=1$, unloading is along the original bulk modulus similar to elastic/ plastic behavior. For $\beta$ between 0 and 1, a combined damage/plastic unloading response results. The effect of $\beta$ is illustrated in Fig. 6.

\section{Concrete perforation calculations}

Figs. 7 and 8 show, respectively, the nominal geometric configurations of the maraging steel ( $\mathrm{T}-250)$ projectile and the concrete target in the experiments conducted by Hanchak, et al. [2]. Only normal impact condition was considered and symmetry prevails. For axisymmetric considerations, the target was approximated by a cylindrical block of $344.2 \mathrm{~mm}$ radius and $178 \mathrm{~mm}$ thickness in the finite element analysis. In the tests, care has been exercised to make certain that the projectiles 
always impacted onto the target block at the center of a reinforcing steel grid to

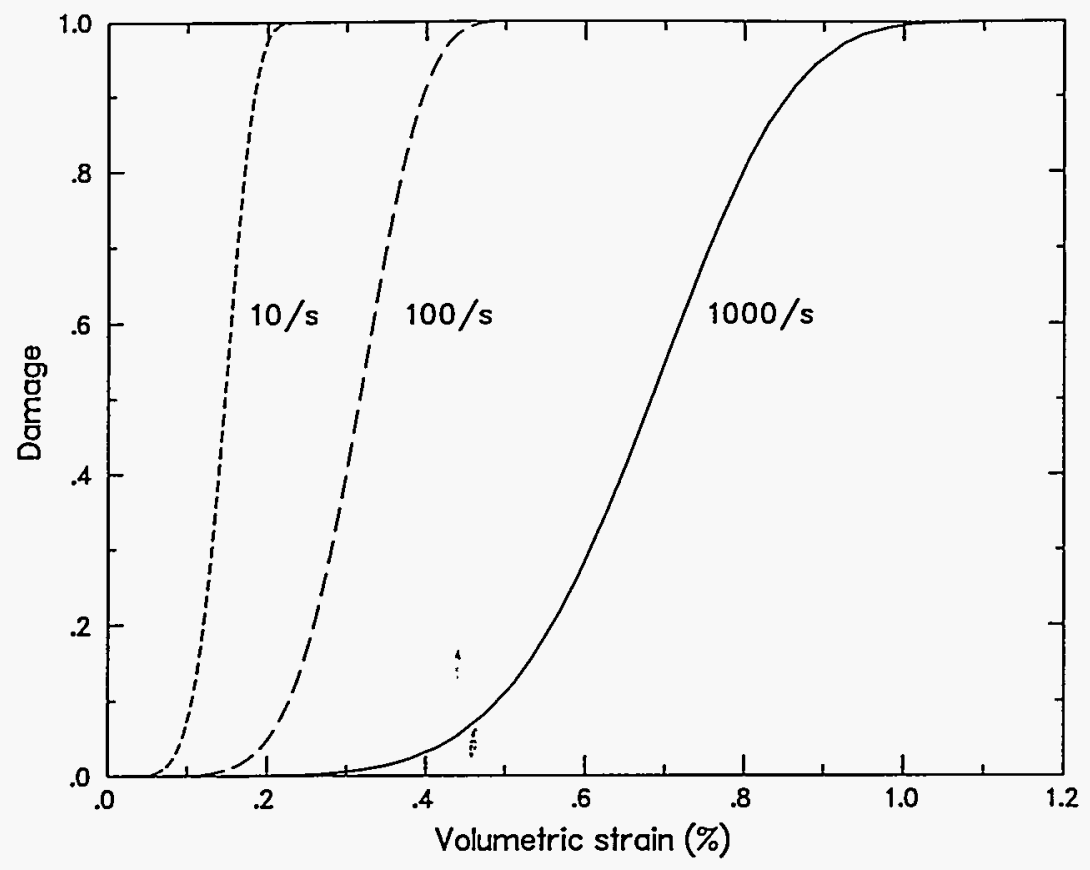

Fig. 3. Damage versus volumetric strain plot.

minimize the effects of the steel reinforcements. For this reason, reinforcing steels have not been included in the finite element analyses. Figure 9 shows the finite element model for the experiment series. The model consists of 9103 quadrilateral

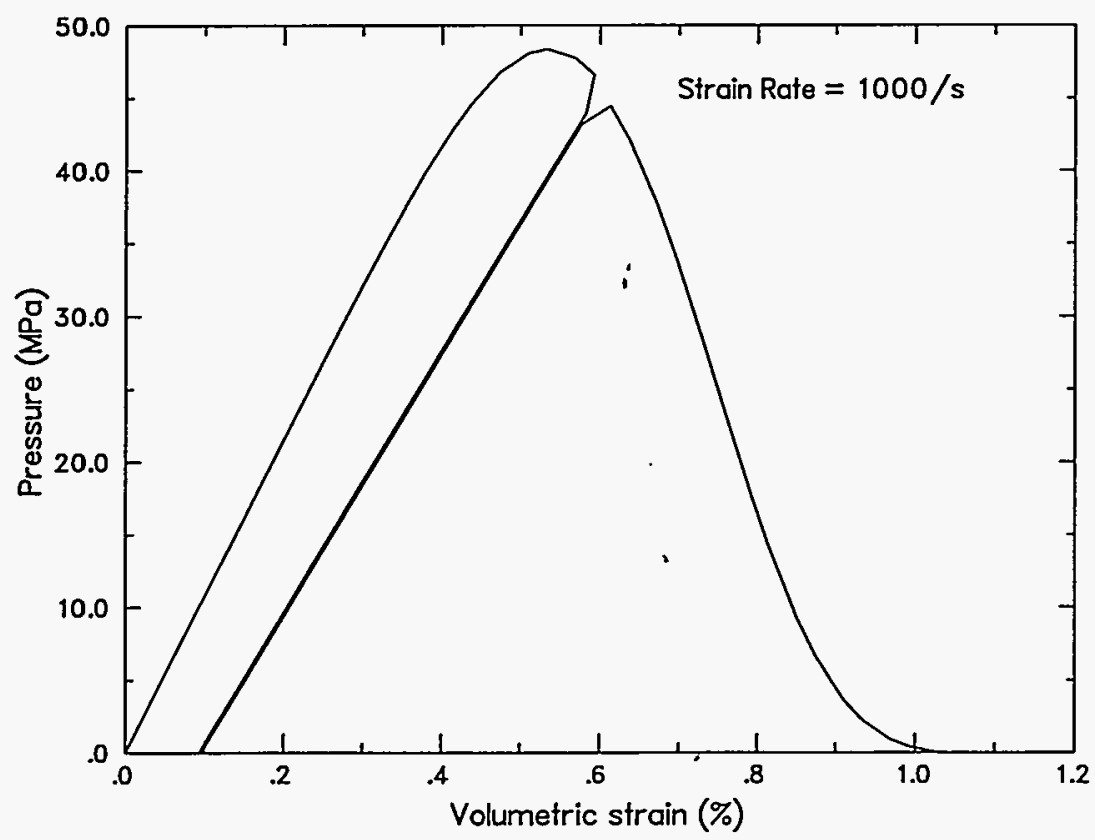

Fig. 4. Cyclic bulk tension response of concrete. 
elements and 9350 nodes. Because of symmetry, only half of the geometry is

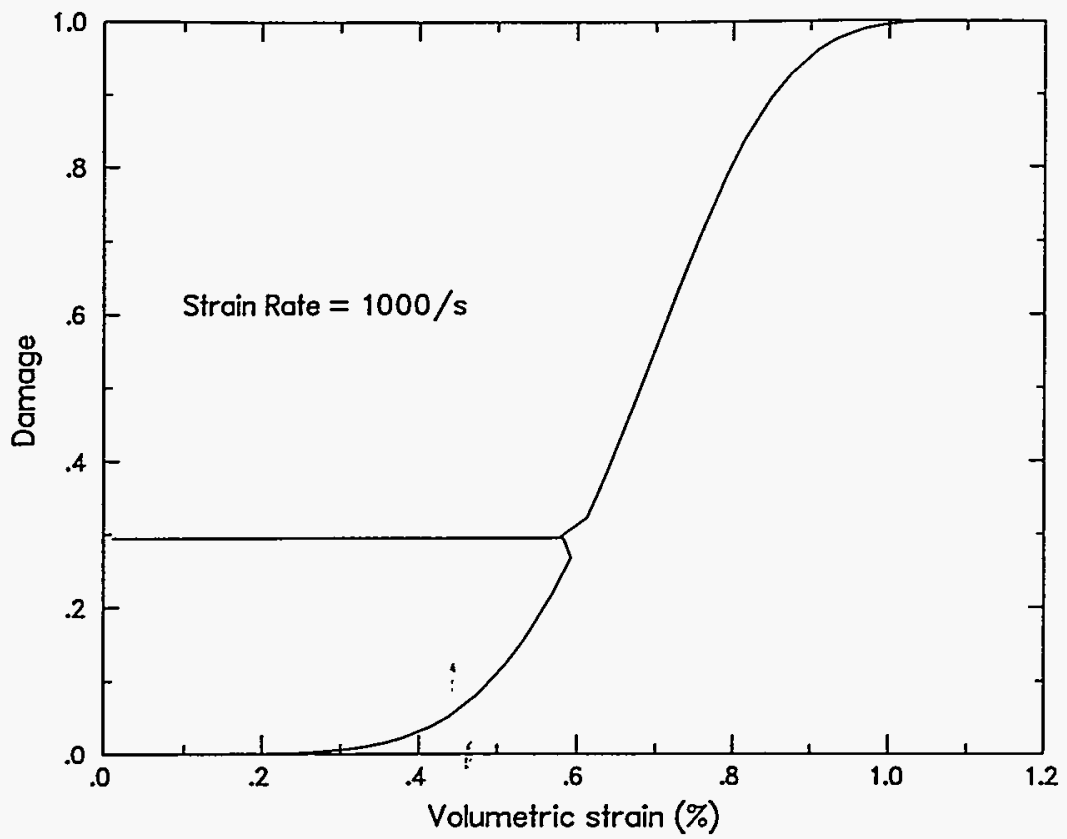

Fig. 5. Cyclic damage behavior.

included. Post experiment observations showed little or no damage was inflicted on the projectiles. Thus, as a first order approximation, the maraging steel (T-250) projectile is modeled as an elastic/perfectly plastic material with the following

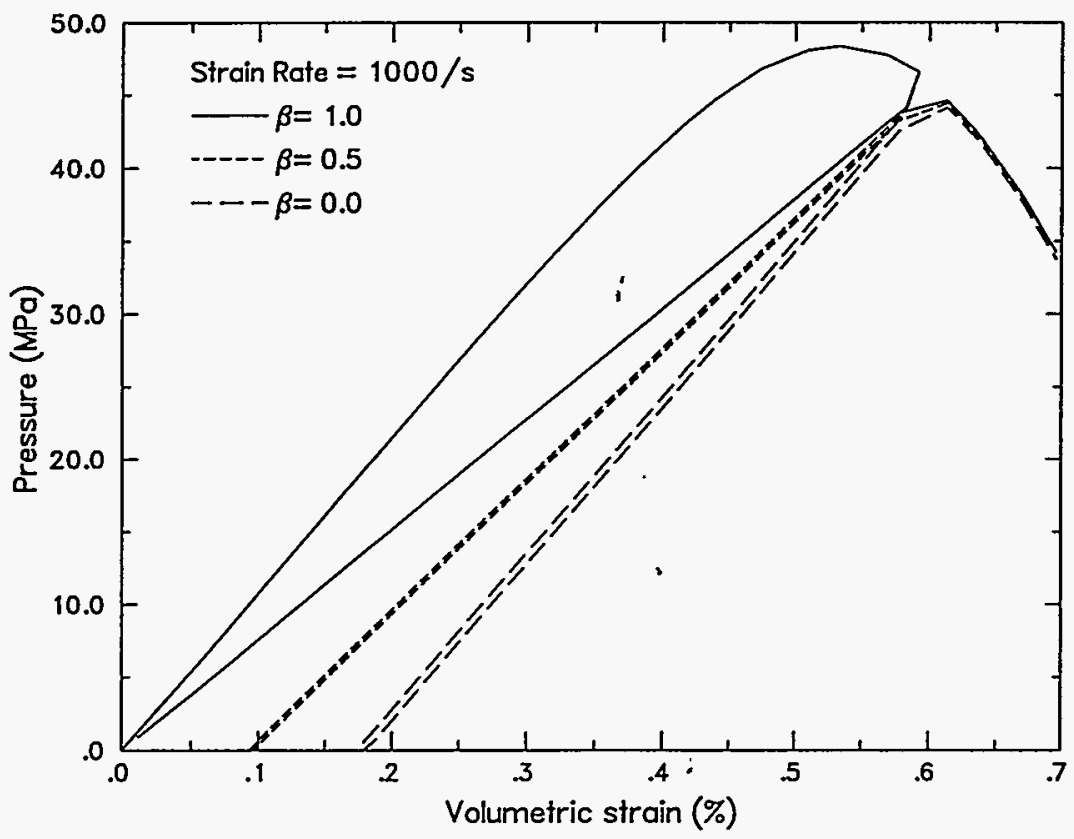

Fig. 6. Effect of $\beta$ on unloading. 
properties [2]: mass density, $8000.0 \mathrm{~kg} / \mathrm{m}^{3}$; Young's modulus, $206.9 \mathrm{GPa}$; Poisson's

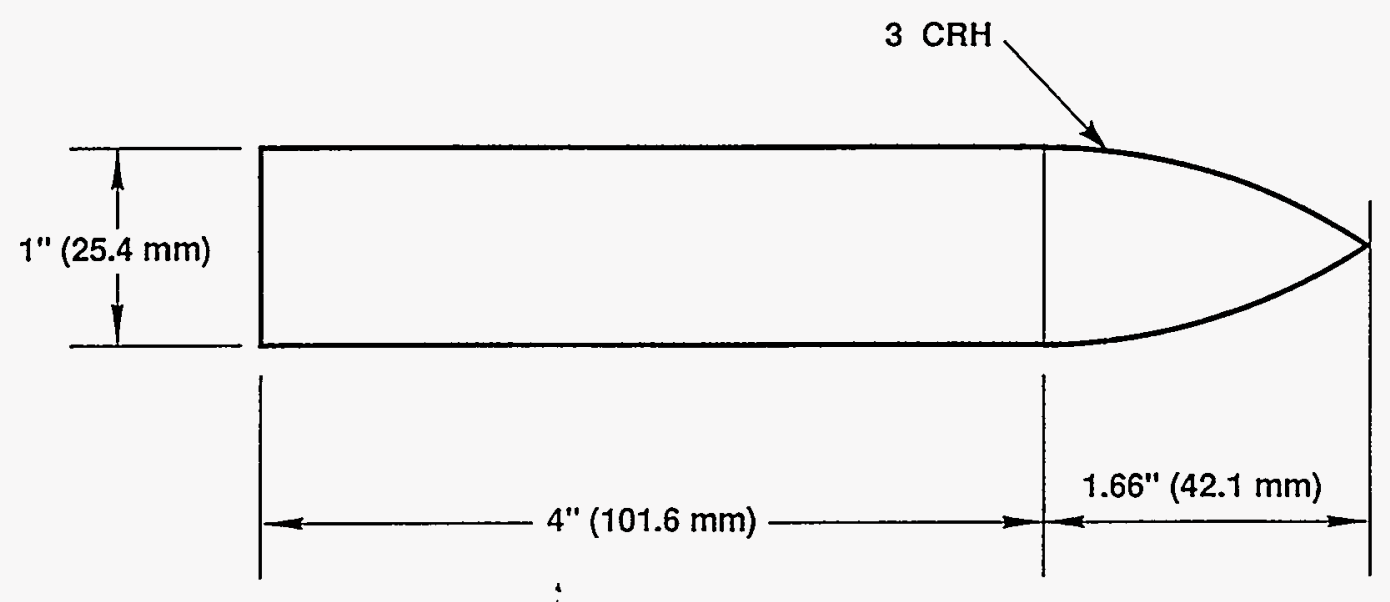

Fig. 7. Steel penetrator geometry.

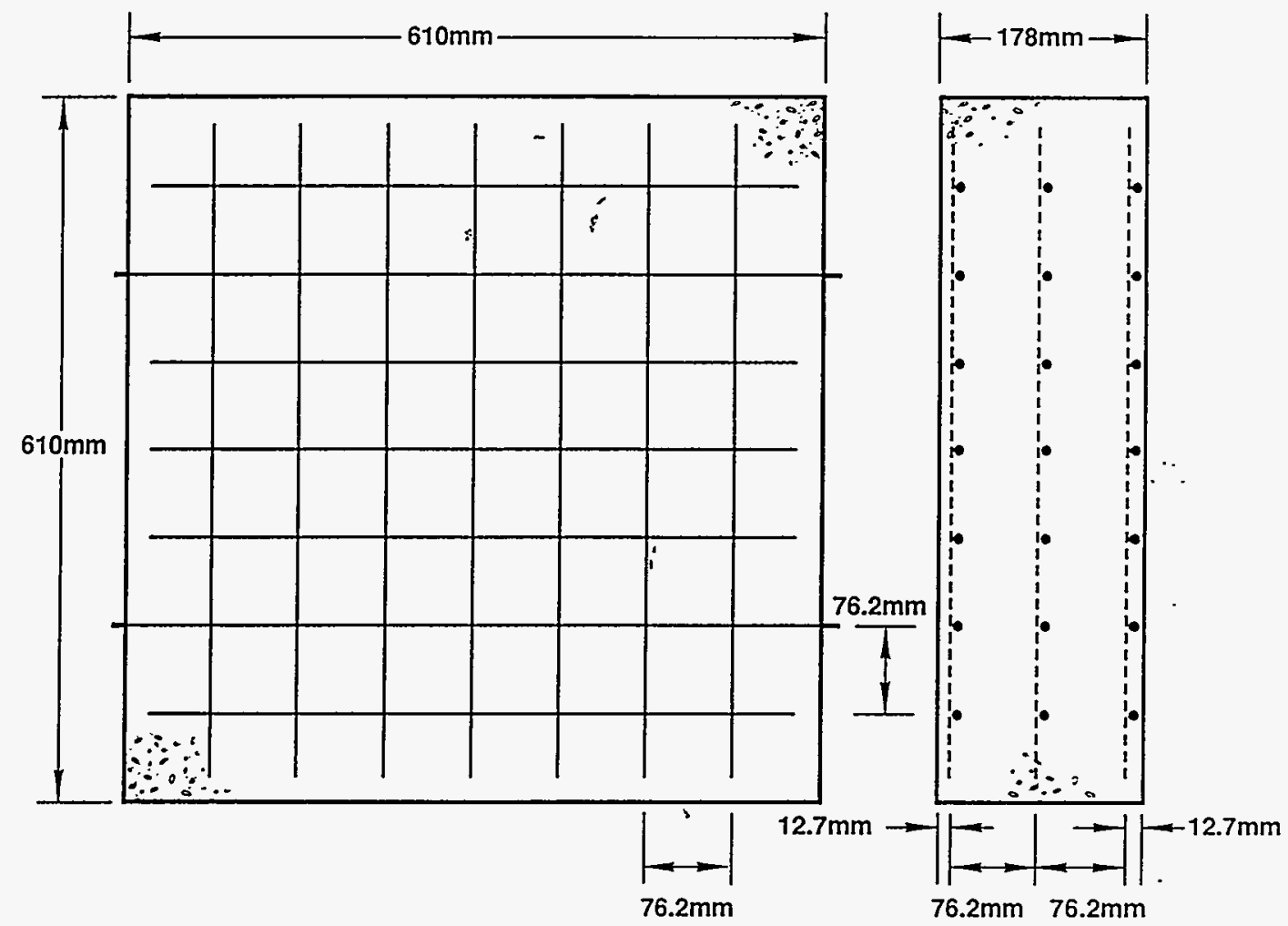

Fig. 8. Concrete target block geometry.

ratio, 0.3; and yield stress, $1.724 \mathrm{Gpa}$. Concrete properties are taken from the last section with the value of $\beta$ fixed at 0.5. The erosion algorithm in LS-DYNA2D [1] was used to alleviate the excessive element distortion problem. Material fracture and 
failure under tension and compression are defined by the magnitude of the damage parameter and the effective plastic strain, respectively, in the erosion algorithm of the

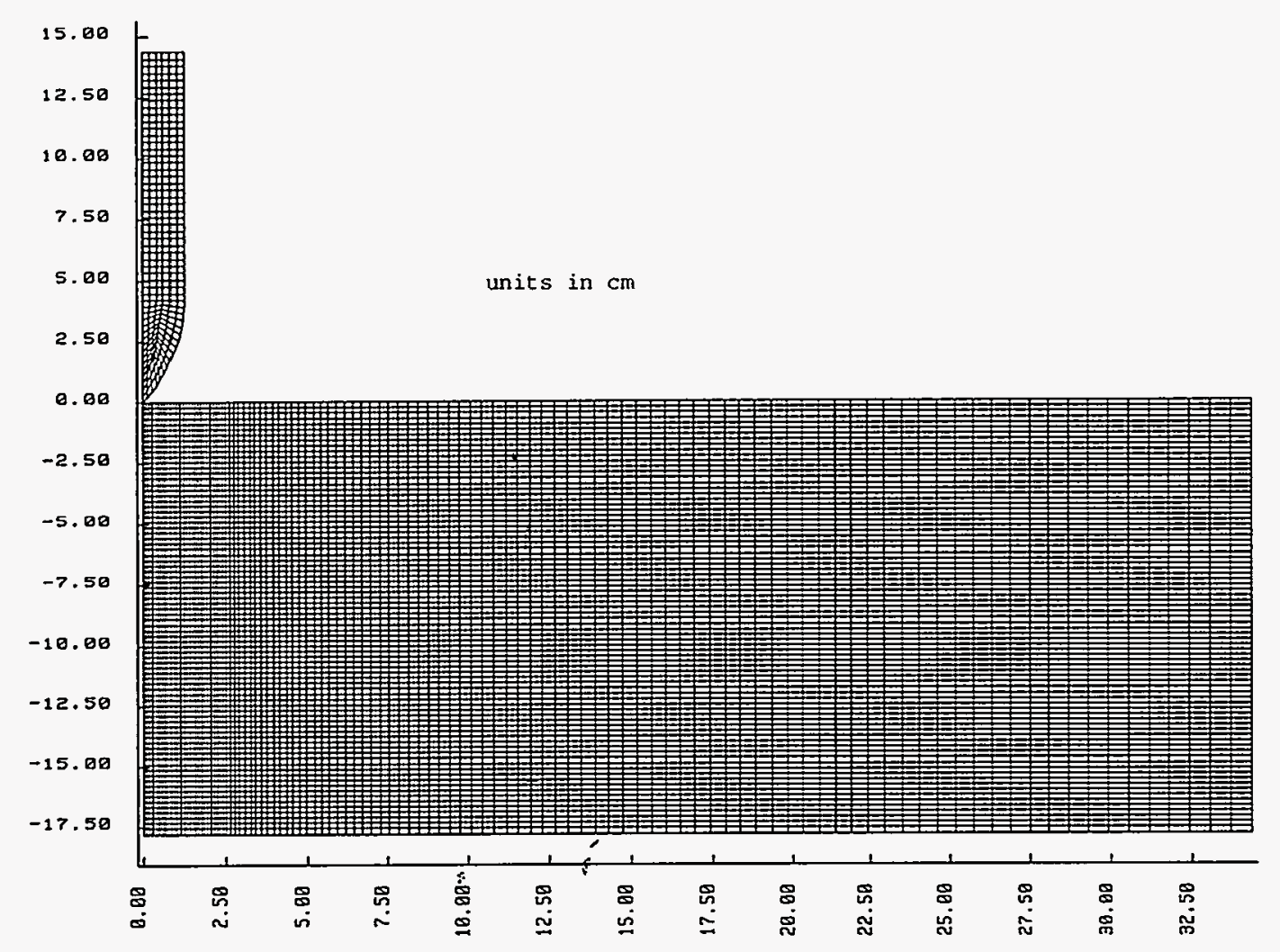

Fig. 9. Finite element for concrete perforation calculations.

LS-DYNA2D code. When the damage or the effective plastic strain in any element reaches the critical value, the element is immediately deleted. The deletion process is irreversible. When the applied load is reversed, deleted material will not be able to offer further resistance. Because actual fracture and failure of the material probably do not occur instantaneously and the broken parts probably can still carry load during load reversal, the critical damage and effective plastic strain used in the numerical analysis are determined by calibrating them against field experimental data. In the experiment series, the impact velocity is the only variable. Thus, the critical fracture and failure parameters were determined by matching calculated and measured data for one impact velocity. Thereafter, the same fracture and failure levels were used to calculate the responses for all other impact velocities. The critical damage and equivalent plastic strain levels for the present set of calculations are determined to be 0.5 and 2.5 , respectively.

Figure 10 shows a deformed mesh plot of a steel projectile perforating a concrete 
slab at $587 \mathrm{~m} / \mathrm{s}$ impact velocity. The figure is a snapshot of the result of calculations

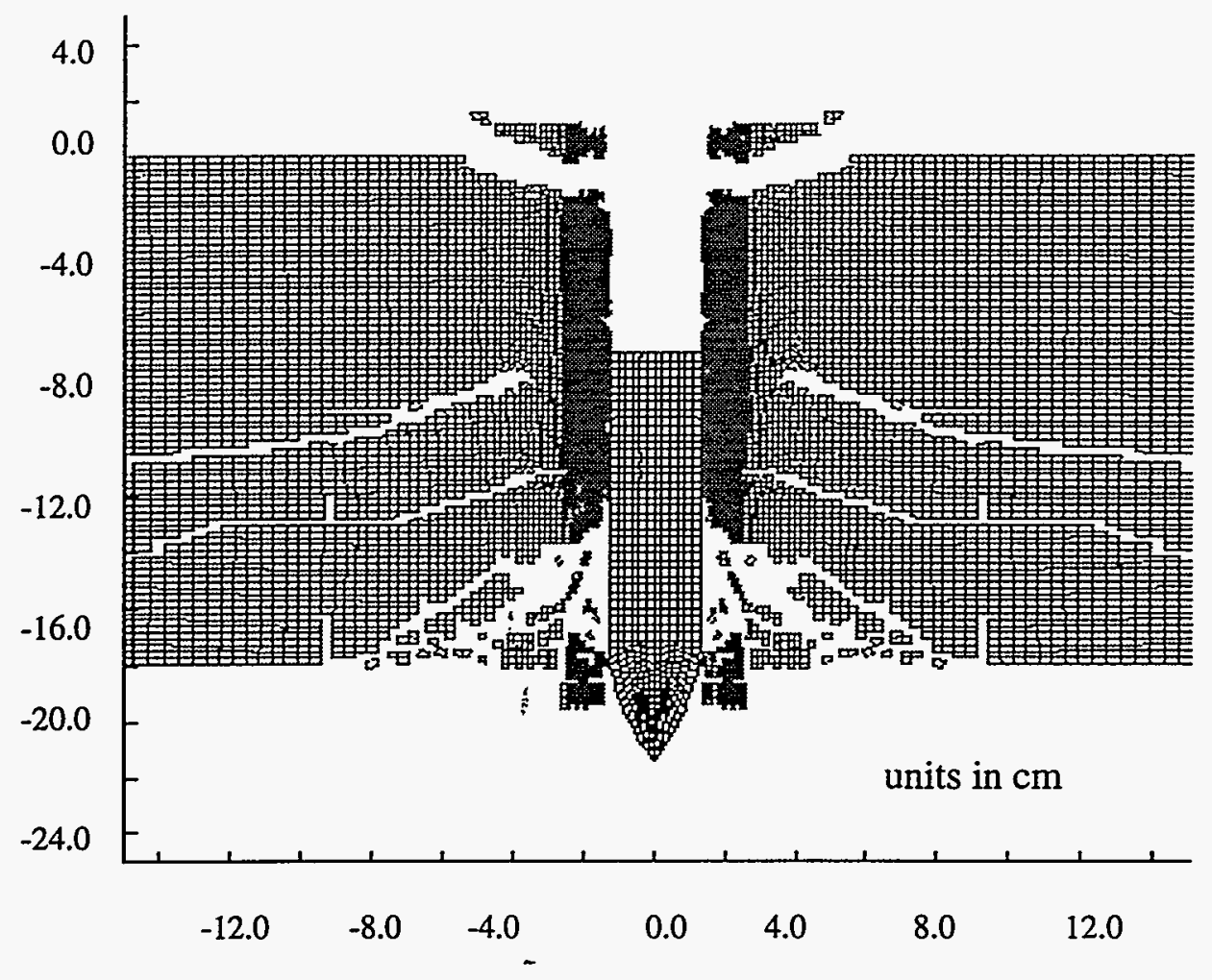

Fig. 10. Deformed mesh plot for $587 \mathrm{~m} / \mathrm{s}$ impact velocity.

from LS-DYNA2D focused on the $14 \mathrm{~cm}$ diameter area around the penetrator and at 500 microseconds after impact. The cratering and hole expansion phases are clearly identified in the target. Qualitatively, calculated results resemble post test observations. Similar results are obtained for all other impact velocities. A typical rigid body velocity history for the penetrator at $587 \mathrm{~m} / \mathrm{s}$ impact velocity is given in Figure 11. The magnitude of the penetrator velocity decreases due to target resistance. After perforation, the velocity of the penetrator remains constant because the target material can no longer offer any resistance. This constant velocity is defined as the residual velocity of the penetrator. If perforation did not occur, the penetrator should have come to rest in the target and should have zero residual velocity. A series of calculations were carried out to obtain residual velocities corresponding to various impact velocities. A comparison between calculated and measured residual velocities is shown in Figure 12. Over the entire impact velocity range, good agreement between calculated and measured data has been found.

\section{Summary}

A numerical study of the dynamic response of concrete slabs impacted by steel projectiles was presented. A microcrack based continuum damage model was applied to capture the brittle tensile fracture observed in the concrete. The tension unloading and 
compression plasticity response of the continuum damage model have been modified

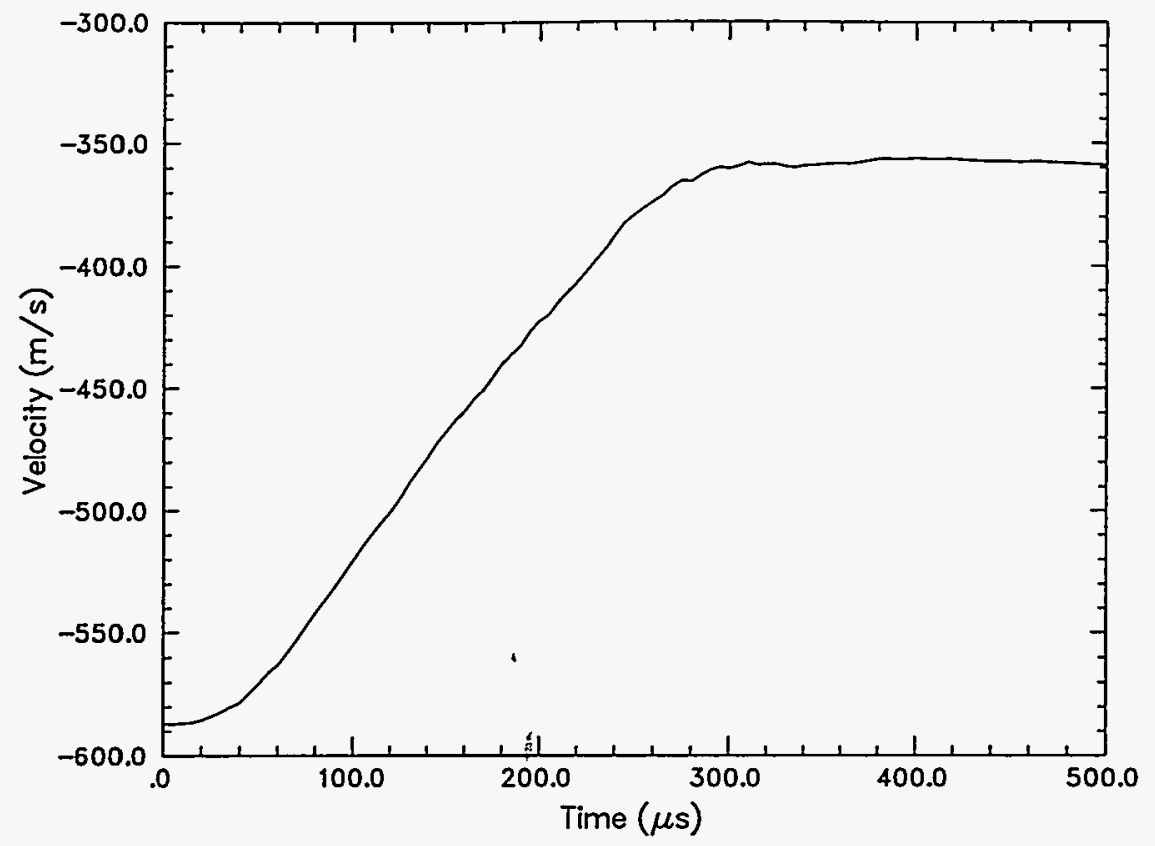

Fig. 11. Penetrator velocity history at $587 \mathrm{~m} / \mathrm{s}$ impact velocity.

to broaden its range of applicability. The erosion algorithm in the transient dynamic finite element code LS-DYNA2D was used to simulate progressive fracturing in con-

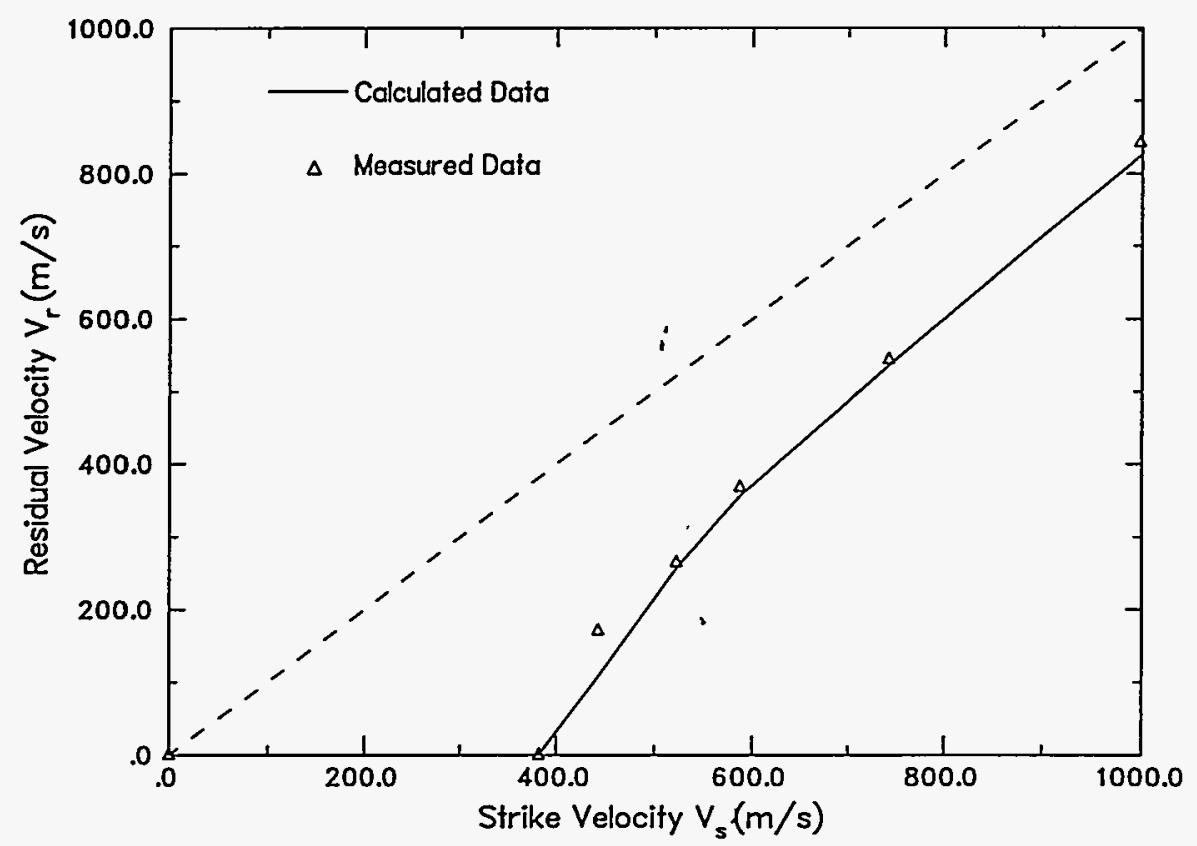

Fig. 12. Comparison between calculated and measured data.

crete. For the range of impact velocities included, good agreement between calculated 
and measured data was obtained.

\section{Acknowledgment}

This work was funded by the Laboratory Directed Research and Development Program, Sandia National Laboratories, under the auspices of the U. S. Department of Energy under Contract Number DE-AC04-94AL85000.

\section{References}

1. Hallquist, J. O. (1990) LS-DYNA2D, an explicit two-dimensional hydrodynamic finite element code, Livermore Software Technology Corporation, Livermore, California.

2. Hanchak, S. J., Forrestal, M. J., Young, E. R., and Ehrgott, J. Q. (1992) Perforation of concrete slabs with $48 \mathrm{MPa}$ and $140 \mathrm{MPa}$ unconfined compressive strengths, International Journal of Impact Engineering, Vol. 12, pp. 1-7.

3. Luk, V. K. and Forrestal, M. J. (1987) Penetration into semi-infinite reinforced-concrete targets with spherical and ogive-nose projectiles, International Journal of Impact Engineering, Vol. 6, pp. 291-301.

4. Luk, V. K. and Forrestal, M. J. (1989) Comment on "Penetration into semiinfinite reinforced-concrete targets with spherical and ogive-nose projectiles," International Journal of Impact Engineering, Vol. 8, pp. 83-84.

5. Chen, E. P. (1993) Numerical simulation of perforation of concrete targets by steel rods, in Advances in Numerical Simulation Techniques for Penetration and Perforation of Solids, E. P. Chen and V. K. Luk, Editors, AMD-Vol. 171, American Society of Mechanical Engineers, New York, pp. 181-188.

6. Krieg, R. D. (1972) A simple constitutive description for soils and crushable foams, SC-DR-72-0883, Sandia Laboratories, Albuquerque, New Mexico.

7. Taylor, L. M., Chen, E. P., and Kuszmaul, J. S. (1986) Microcrack-induced damage accumulation in brittle rock under dynamic loading, Journal of Computer Methods in Applied Mechanics and Engineering, Vol. 55, pp. 301-320.

8. Thorne, B. J. (1990) A damage model for rock fragmentation and comparison of calculations with blasting experiments in granite, SAND90-1389, Sandia National Laboratories, Albuquerque, New Mexico.

9. Chen, E. P. (1986) Continuum Damage Mechanics Studies on the Dynamic Fracture of Concrete, in Cement-Based Composites: Strain Rate Effects on Fracture, S. Mindess and S. P. Shah, Editors, Materials Research Society Symposia Proceedings Volume 64, Materials Research Society, Pittsburgh, Pennsylvania, pp.63-77.

10. Budiansky, B. and O'Connell, R. J. (1976) Elastic moduli of a cracked solid, International Journal of Solids and Structures, Vol. 12, pp. 81-97.

11. Grady, D. E. and Kipp, M. E. (1980) Continuum modeling of explosive fracture in oil shale, International Journal of Rock Mechanics and Mining Science, Vol. 17, pp. 147-157.

12. Grady, D. E. (1980) The mechanics of fracture under high-rate stress loading, Preprints of the William Prager Symposium on Mechanics of Geomaterials: 
Rocks, Concrete and soils, Z. P. Bazant, Editor, Northwestern University, Evanston, llinois, pp. 149-188.

13. Englman, R. and Jaeger, Z. (1987) Theoretical aids for the improvement of blasting efficiencies in oil shale and rocks, AP-TR-12/87, Soreq Nuclear Research Center, Yavne, Israel.

14. Drucker, D. C. and Prager, W. (1952) Soil mechanics and plastic analysis or limit design, Quarterly of Applied Mathematics, Vol. 10, pp. 157-165.

15. Kipp, M. E., Grady, D. E. and Chen, E. P. (1980) Strain-rate dependent fracture initiation, International Journal of Fracture, Vol. 16, pp. 471-478. 